\title{
Uninsured by Choice? A Choice Experiment on Long Term Care Insurance
}

\author{
Faical Akaichi ${ }^{\text {(i) }}$ Joan Costa-Font ${ }^{(i i)}$ and Richard Frank ${ }^{\text {(iii) }}$ \\ ${ }^{(i)}$ Land Economy Environment and Society, SRUC Edinburgh, UK

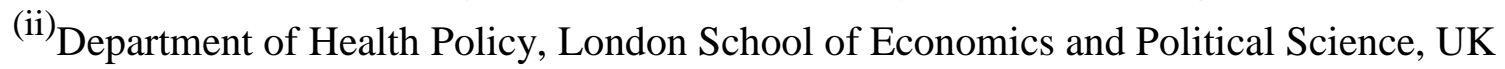

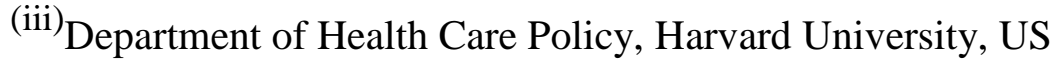

Contact author: Joan Costa-Font, Department of Health Policy, London School of Economics and Political Science, UK. E-mail: j.costa-font@1se.ac.uk 


\begin{abstract}
We examine evidence from two unique discrete choice experiments (DCE) on long term care insurance and several of its relevant attributes, and more specifically, choices made by 15,298 individuals in the United States with and without insurance. We study the valuation of the following insurance attributes, namely daily insurance benefit, insurance coverage, the compulsory and voluntary nature of the insurance policy design, alongside the costs (insurance premium) and health requirements This paper investigates respondents' preferences and willingness to pay (WTP) for these care insurance's attributes using a random parameter logit model, and assess the heterogeneity of choice responses using demographic, socioeconomic and attitudinal motivations to segment response to insurance choices. We find that an increase in the insurance premium by an additional 100US\$ would reduce insurance uptake by 1pp. Insurance policy uptake is higher when it provides benefits for the lifetime (the monthly marginal WTP being \$178.64), and voluntary (the monthly marginal WTP increases by an extra \$74.71) as opposed to universal, and when it forgoes health checks (the monthly marginal WTP increases by an extra 28US\$).
\end{abstract}

Keywords: long term care insurance, constrained choices, self-insurance, behavioural constraints, insurance design.

JEL: 118. 


\section{Introduction}

The market for long term care insurance (LTCI), an insurance that compensates individuals in the event of needing long-term services and supports (LTSS), has shown a slow development since its inception four decades ago in the United States. Part of the explanation may lie with demand-side factors; however, revealed preferences for insurance purchase approaches may hide the underlying individual's take up intentions to insure long term care, and especially how such choice intentions depend on the insurance design features (e.g., premium, size of the deductible and the duration of benefit etc). In addition, observed purchases may also obscure the heterogeneity of such intentions are across individuals. The cost of LTSS is one the largest financial risks that older adults face in most high-income nations. The average private pay price of a private room nursing home stay in 2017 was between $\$ 85,800$ and $\$ 97,500$ a year and Medicare only covers post-acute care but not cover LTSS (Genworth, 2017). About half of adults that reach the age of 65 can expect to use some long-term services and supports before they die (Favreault and Dey, 2015). Among those that will use LTSS, the expected present discounted value of the services that they would use was estimated at $\$ 133,700$ in 2015 dollars. Roughly 5\% of men and 12\% of women age 65 and over will incur costs for LTSS of over \$250,000 in present discounted 2015 dollars before they die (Favreault and Dey, 2015). At first glance these figures suggest that LTSS appears to be a textbook example of an insurable risk. Nevertheless, the market for LTCI in the U.S. seems to be failing (Bergquist et al. 2018, Brown and Finkelstein 2007, 2008). It has not grown over the last four decades, and in fact it has declined slightly in the last few years due to several product design failures (e.g., insurance underwriting and inefficient pricing). However, there are significant behavioral factors that can explain such insurance choices such as risk misperception, "denial", present bias in addition to limited affordability (Brown et al, 2012). This paper aims to contribute to 
the understanding of the limited the demand for LTCI, focusing on behavioral dimensions influencing such decisions.

Decision-making regarding LTCI is unique in a number of ways. First, insurance decisions are largely state dependent and emotional (due to the loss of independence in the event of disability and the role of family in care of older adults) (Loewnstein et al. 2013). Second, individuals are not always well equipped to assess their risk of disability, let alone its duration (Kunreuther et al, 2002), and face limited experience in making similar insurance choices unless they were involved in a family member's arrangements (Coe et al, 2015). Third, although family norms with regard to intergenerational caregiving obligations might have changed over time, individual behavior might still be grounded on traditional default social norms, and hence their LTCI decisions may be effected by a type of cultural inertia. Finally, insurance products are often complex and thus hard to understand, and they entail large immediate premium costs to protect against risks that are primarily 30 to 40 years off. Such choices are vulnerable to present bias and prone to procrastination as they are fewer pressing decisions relative to other demands. However, we know little about what dimensions of the insurance design influence such decisions. Here we explore questions such as whether a long elimination period (deductible) and a lower premium make policies more attractive? And, is medical underwriting an important deterrent to purchase of LTCI?

There is evidence that the current LTCI purchasers represent only a small share of those who may be interested in purchase of LTCI. For example, industry reports suggest that insurance brokers divert many potential consumers due to their assessment of the potential buyer's ability to pay or their health status. Even when individuals buy LTCI, they often lack understanding of key features of their coverage and choose dominated options (Lowenstein, 2013). Gabaix and Laibson (2006) show that a significant group of consumers make systematic errors in choosing between insurance products as they are overwhelmed by choice. Gottlieb and Mitchell (2015) find that framing also matters in explaining insurance take up, and McGarry et al (2017) find that greater cognitive capacity increased purchase decisions. One implication of this is that observed purchases 
in the market offer only a limited ability to make inferences about demand behaviour. These observations also suggest that if insurance products are made more user friendly that can promote uptake of insurance.

This paper approaches the task of understanding the demand for LTCI by studying consumer choices outside of a real market setting, using data from a large discrete choice experiment (DCE), the 2014 Survey of Long-Term Care Awareness and Planning. The DCE was designed to identify factors that influence the demand for LTCI, which in turn allows for the estimation of the willingness to pay specific features of LTCI. It also permits an assessment of the rates at which individuals' trade-off different policy "attributes" that are salient in the purchase decision (e.g., duration of coverage, benefit amount). We do not interpret the resulting demand as normative nor is it fully reflective of actual market behaviour (Louviere et al, 2011). Instead, respondents were asked to compare a series of paired hypothetical LTCI policies, described by specific attributes, and to select their preferred alternative, including a third option of "neither". An important advantage of conducting this experiment in the US, is that long term care insurance has been long available, and hence individuals may be more likely to have been exposed to LTCI than in most other countries. Other studies carried out in European settings where there is no insurance are likely to be more affected by a hypothetical nature of the DCE. It is worth noting that estimates based on models of hypothetical health insurance choices have been shown in some cases to provide similar elasticities to observational data from actual insurance markets (Royalty and Hagens, 2005).

A strength of DCE compared to other stated preference survey methods is that preferences are measured through a series of "comparison shopping" exercises. Individuals are assumed to compare the different insurance options and select the alternative containing the most preferred combination of attributes. This technique is widely used in health and environmental decisions and 
offers a decision-making scenario similar to what people actually face real insurance decisions. Furthermore, the ratio between the willingness to pay (WTP) of two alternatives allows one to compute the marginal rate of substitution between them.

Some prior studies have employed DCE in similar insurance contexts. Allaire et al (2016) found that take up of LTCI is limited to individuals whose wealth exceeds $\$ 100,000$ and declines with the presence of a child living nearby. In contrast, we provide a complete analysis of the choice experiments that enables us to predict a decision maker's choice of one discrete alternative from a choice set, and inform policy analysis on what insurance characteristics, which are mutually exclusive and exhaustive, are most likely to attract enrollees to LTCI. In a health insurance setting, Krueger and Kuziemko (2013) conducted a survey experiment to elicit the willingness to pay for hypothetical plan offerings in a large sample of uninsured Americans. They elicited self-reported willingness-to-pay for health insurance by uninsured Americans. However, the study did not use a discrete choice format.

Referring more strictly to long-term care insurance, there are only a small number of studies in European countries where there is no market for LTCI. Relatedly, Costa-Font (2017) employed a survey experiment to elicit individuals' willingness to pay to avoid institutionalization. Costa-Font and Rovira (2008) employed a contingent valuation survey to elicit demand for LTCI using a referendum in Spain and found that only one fifth of the population was willing to pay a premium for such insurance. Brau and Lipi Bruni (2008) carried out a choice experiment on long term care coverage in a setting without insurance (Emilia-Romagna, Italy). They explored some important insurance attributes such as the cost of the policy, cost-sharing and the 'voluntary vs. compulsory' nature of the policy. Other studies have used DCE to study the demand for long-term care itself and term life insurance. These include the study of Nieboer et al (2010) estimating the preferences for long term care using a discrete choice format to a sample of over a thousand individuals in the Netherlands. They presented study participants with four scenarios and found that those without a 
partner and with dementia exhibited a higher demand for long-term care services. Braun et al (2016) show, using a DCE in Germany, the influence of premium, brand and critical illness dimension in explaining insurance choices.

Our results suggest that the average willingness to pay for lifetime insurance policy is well below existing market rates (that are typically under-written), and we attribute this to both traditional and behavioral market failures. This is reflected by the fact that in the United States such policies have nearly disappeared from the market place (AHIP, 2017). Our results broadly suggest that subsidizing the purchase of insurance plans could significantly reduce the population without private LTCI and may be welfare increasing. We also identify the value consumers place on a number of important LTCI attributes. We rely on a latent class type of discrete choice model to explain some of the relevant sources of heterogeneity. In addition to the information about respondents' choice behavior, we rely on the respondents' socio-demographic characteristics and attitudes to classify them.

The remainder of the paper is organized in the following way. The next section describes the choice experiment and its magnitude. The third section describes the empirical strategy employed and the models used to analyze the discrete choice experiments (DCE) including the latent class model employed. Section four provides the results and a final section offers some concluding remarks.

\section{A Choice Experiment}

The DCE we examine was part of a larger Long-Term Care Awareness and Planning Survey commissioned by the U.S. Department of Health and Human Services to examine consumer preferences for specific features of individual LTCI policies (e.g., benefit levels, duration of 
coverage, sponsorship) ${ }^{1}$. The sample is made up of 24,878 noninstitutionalized adults $40-70$ years of age and a total of 15,298 persons responded to the survey, yielding a $61.5 \%$ response rate. The data were collected in August-September 2014 through a survey that made use of an established internet panel run by KP, GfK. The company assigns no more than one survey per week to members. The recruitment was based on residential addresses that cover approximately $97 \%$ of U.S. households and households that do not have an Internet connection received a free computer and Internet service if they joined the panel. Survey respondents received e-mail notifications and reminders to fill out the survey and were rewarded for their participation with 10,000 KP "points" (equivalent to about \$10) that can be exchanged for merchandise and other prizes. Only $13.2 \%$ of the households interviewed responded that they currently had LTCI. This is a figure that is in line with the Health and Retirement Study (HRS) data from that period.

The survey contains a long list of question on attitudes towards long-term care that we have examined in detail alongside the DCE. That information allows us to identify the different views that underpin the potential demand for LTCI. The use of the DCE is important because other survey experiments have shown that individuals are likely to anchor their estimates on the first options presented to them (Krueger and Kuziemko, 2013). Respondents completed two related sets of DCE questions, which we refer to below as "DCE1" and "DCE2". They involved questions about plans involving six attributes: daily benefit amount, benefit period, elimination period (deductible), health requirements, type of insurer, and monthly premium. DCE2 included all attributes from DCE1 plus an attribute of whether participation was voluntary or mandatory in the LTCI plan. This allows us to identify the value of a "voluntary" insurance scheme. Since DCE2 is more complete, the analysis reported here was carried using the data from DCE2. The baseline estimation model is a random parameter logit model. This is the most appropriate model to capture heterogeneity across individuals, since it does not impose any restriction on the number of respondent classes (i.e., the number of classes are equal to the number of respondents). Because $19 \%$ of respondents chose the

\footnotetext{
${ }^{1}$ The authors did not participate neither in the design nor in the implementation of the survey. We are just users of the data.
} 
opt-out alternative in all the choice sets in DCE2, their responses were excluded from the data to avoid that they distort the responses of the other respondents.

\section{Empirical Strategy}

\subsection{Experimental design}

The DCE survey consisted of a choice section and a questionnaire. In the choice section, participants were successively provided with 8 different choice sets and were repeatedly asked to choose between two different LTCI policies and an opt-out alternative. Each LTCI policy displayed in the first five choice sets (DCE1) is described in terms of the six attributes noted earlier. The LTCI policies shown to respondents in the last three choice sets (DCE2) are described in terms of seven choice sets: the six aforementioned attributes plus the attribute "type of enrollment". A description of the seven attributes as well as their corresponding levels is displayed in Table 1.

\section{[Insert Table 1 about here]}

The first dimension of benefit design studied, in addition to the premium, is the so-called 'daily benefit'. Data from 2015 suggests the average the daily benefit was below \$159/ nursing home day and $\$ 152$ per home care day, and the premium is linked typically to the benefit of the policy (AHIP, 2017). The typical policy would offer a deductible (or elimination) period of 93 days (in 2015). The mean duration of coverage for nursing home care was 3.8 years, while approximately one third of existing policies would extend the benefit to a lifetime and they are largely not being sold anymore (American Association for Long-Term Care Insurance, 2015). Furthermore, nearly all policies are subject to medical underwriting that limits the offer of coverage to relatively healthy individuals (Cohen, Kaur, \& Darnell, 2013). The underwriting standard have become more stringent in recent years (O’Leary, 2012). Finally, other important dimensions are the type of insurer (public/private) and the type of enrollment (voluntary/compulsory). 
Given all the attribute levels included in the design of the first and second DCE, we draw upon a full factorial design of 1024 LTCI policies (and 2048 the second). The DCE presented followed best practices in generating an efficient design that enabled the estimation of the parameters (i.e., marginal utilities for the aforementioned insurance attributes) with relatively small standard errors ${ }^{2}$. The final design consisted of 500 choice sets that were in 100 blocks of 5 choice sets each initially for the first DCE (DCE1). This process was then repeated for the second DCE with an additional choice (DCE2). An efficient design of 300 unique choice sets was obtained. The 300 choice sets were broken into 100 blocks of 3 choice-sets each. Thus, each respondent was first asked to complete only 5 choice sets. Then, she was given information about the seventh attribute ("type of enrolment") and asked to answer three more choice questions.

In each choice set, respondents were asked to mark the alternative they prefer most (i.e., Policy A, Policy B or No insurance $)^{3}$, and within each block, the choice sets were randomly ordered. Furthermore, the A/B policies were randomly ordered between left and right sides of the screen too. An illustration of two choice sets used in DCE1 and DCE2 are, respectively, displayed in both Figure 1 and Figure 2.

\section{[Insert Figure 1 and 2 about here]}

In addition to responding to the eight choice questions, respondents were also asked to answer several debriefing questions. The debriefing questions were asked to collect information on the following issues: "Risk of Needing Long-term care", "Psychological Characteristics, Knowledge, Skills, and Experience", "Beliefs and Concerns About Long-Term Care", Retirement and LongTerm Care Planning”, "Information Gathering and Decision Making About Insurance”, “Core

\footnotetext{
${ }^{2}$ An alternative design with a full set of choices would be time consuming and cognitively challenging given such large number of policies.

${ }^{3}$ Since it is not realistic to force respondents to choose one of the two insurance policies described in each choice set, an opt-out alternative (no insurance) was included in each choice set.
} 
Demographic and Socioeconomic Information", and "Comparing Insurance Policies with a Combination of Features"

\subsection{DCE Modelling}

Following Lancaster's (1966) view of products as bundles of attributes, the benefits that individuals derive from the consumption of a product is assumed to be equal to the sum of their benefits for each of the attributes that constitute the product of interest. Consequently, individual $i$ 's value function $\left(U_{i j t}\right)$ that is specific for each $j^{\text {th }}$ alternative at the $t^{\text {th }}$ choice occasion takes the form:

$$
U_{i j t}=V_{i j t}+\varepsilon_{i j t}
$$

$V_{i j t}$ captures the deterministic component and $\varepsilon_{i j t}$ the random component. $\varepsilon_{i j t}$ is assumed to be independent and identically distributed. Assuming that the deterministic component is linear-inparameter, equation (1) can be written as:

$$
U_{i j t}=\beta X_{i j t}+\varepsilon_{i j t}
$$

Where $\beta$ denotes the vector of unknown utility parameters that are associated with the product attributes $X_{i j t}{ }^{4}$.

The variables corresponding to the attributes "Daily Benefit", "Deductible Period" and "Monthly Premium Cost" were coded as continuous variables using their original values. For each of the rest of the attributes (L-1) dummy variables were generated, where $\mathrm{L}$ is the number of levels of the attribute. The $\mathrm{L}^{\text {th }}$ level of each attribute was omitted during the estimation of the econometric model to avoid the problem of multicollinearity. Furthermore, the omitted levels "1 year", "Healthy and not Disabled", "Federal Government", and "Universal Plan" corresponding to the attributes "Benefit Period”, "Health Requirements”, “Type of Insurer”, “Type of Enrollment”, respectively,

\footnotetext{
${ }^{4}$ In this study, $X_{i j t}$ represent the following level of attributes "Daily Benefit" (DB), "Benefit Period-Lifetime" (BPL), "Benefit Period-5years" (BP5), "Benefit Period-3years" (BP3), "Deductible Period” (DP), "Health Requirement" (HR), "Type of Insurer" (TI), "Type of Enrolment" (TE), and "Monthly Premium Cost" (COST). A tenth variable "None" (NONE) was also considered to estimate respondents' preferences for the opt-out option.
} 
were set as the baseline levels. Thus, the estimated parameters represent respondents' demand response to the included levels with respect to the baseline level.

The conditional logit (CL) model (McFadden 1974) is the workhorse model for analyzing discrete choice data. However, its assumptions (i.e., homogeneity of respondents' preferences and the alternatives included in any choice set are treated by respondents as independent) were viewed as unrealistic and found to generally not hold (Hensher et al., 2015). Train (1998) proposed a less restrictive model (Random Parameter Logit (RPL)) that allows individuals' preferences to be heterogeneous and the assumption of the Independence of Irrelevant Alternatives to be relaxed. In the RPL, at least some of the parameters are specified as random. In other words, each individual is considered to have a unique set of preferences, reflected in the individual parameters $\beta_{i}{ }^{5}$. In the RPL, the conditional choice probability that individual $i$ choose an alternative $j$ at a choice occasion $t$ is specified as:

$$
P\left(j \mid X_{i t}, \beta\right)=\prod_{t=1}^{T}\left[\frac{\exp \left(\beta_{i}^{\prime} X_{i j t}\right)}{\sum_{k=1}^{J} \exp \left(\beta_{i}^{\prime} X_{i k t}\right)}\right]
$$

The unconditional choice probability is the expected value of the logit probability integrated over all possible values of $\beta$ and weighted by the density of $\beta$ :

$$
P\left(j \mid X_{i t}, \Omega\right)=\int_{\beta} P\left(j \mid X_{i t}, \beta\right) f(\beta \mid \Omega) d \beta
$$

Since the expression in (4) does not have a closed form solution, it is therefore approximated through simulation methods. In particular, $\mathrm{R}$ draws of $\beta_{\text {ir }}$ are taken from the distribution $f(\beta \mid \Omega)$.

\footnotetext{
${ }^{5}$ We estimated both the conditional logit and the RPL model. We found that the RPL model fits better the data. Most importantly, the results from the RPL model showed that the estimated standard deviations of 7 out of 10 random parameters considered in the analysis were found to be statistically significant, indicating that respondents preferences for the attributes "Daily benefits", "Benefit Period-Lifetime", "Health Requirement", "Type of Insurer", "Type of Enrolment" and "Cost" are heterogeneous. Thus, we concluded that the RPL model is the choice model that we should use to assess respondents' preferences and willingness to pay for LTCI attributes.
} 
For each draw, the choice probability is calculated. Then the resulting probabilities from the $\mathrm{R}$ draws are averaged. The simulated log-likelihood (SLL) for all respondents is estimated via maximum likelihood procedures and is calculated as:

$$
S L L=\sum_{i=1}^{I} \sum_{t=1}^{T} \ln \left(\frac{1}{R} \sum_{r=1}^{R} \frac{\exp \left(\beta_{i r} X_{i j t}\right)}{\sum_{k=1}^{J} \exp \left(\beta_{i r} X_{i k t}\right)}\right)
$$

In this study, all the parameter estimates were assumed to follow a normal distribution.

The results from the estimation of RPL model showed that respondents' attitudes are highly heterogeneous. While the RPL model controls and accounts for heterogeneity, it does not explain the source of heterogeneity. In fact, only knowing that the preferences for the considered attributes vary across respondents is of limited practical use.

To gain more information on the likely position of each respondent in the sample distribution, we computed the individual-specific distributions using the approach of conditional distributions that was pioneered by Train (2003). The idea was that once individual preferences are obtained, individual WTP would be computed and used for posterior analyses such as the identification of different segments of respondents with similar preferences. For example, based on the computed individual-specific WTP, the average WTP for voluntary LTCI provided by a private company is $\$ 122$ and $\$ 12$, respectively. Their respective confidence intervals are [-87265.82, 87573.77] and [157673.20, 221288.50]. After establishing that using the conditional distributions approach to assess the heterogeneity of respondents' preferences and WTP is inappropriate, we turned our focus to the use of a different alternative termed latent class model (LCM) for discrete choice analysis (Greene and Hensher, 2003). 
The LCM for discrete choice analysis is less flexible than the random parameter logit (i.e., it assumes that the distribution of respondents' attitudes is discrete and not continuous) but it helps one to understand the sources of the heterogeneity in individual preferences. The LCM groups respondents in a finite number of classes, where membership in a specific class is based on respondents' preferences for the attributes of the LTC insurance and their characteristics (e.g.,sociodemographic factors). The LCM assumes that respondents' preferences are homogeneous within each class but are heterogeneous across classes. Grouping respondents with homogeneous preferences in a finite number of classes is relevant for decision-makers because it helps them to understand the heterogeneity of individual preferences (hence, the distribution of welfare impact) and, most importantly, to tailor, e.g., their marketing campaigns and their outreach strategies to meet the needs of specific consumers segments. This will, in turn, make those campaign and strategies more cost-effective.

In the LCM for discrete choice analysis, the log likelihood for all respondents is:

$$
\ln L=\sum_{i=1}^{N} \ln \left[\sum_{q=1}^{Q} H_{i q}\left(\prod_{t=1}^{T_{i}} P_{i t \mid q}(j)\right)\right]
$$

Where $H_{i q}$ denotes the prior probability for class $q$ for individual $i$. For this study, the form of the prior probability is a multinomial logit:

$$
H_{i q}=\frac{\exp \left(z_{i}^{\prime} \theta_{q}\right)}{\sum_{q=1}^{Q} \exp \left(z_{i}^{\prime} \theta_{q}\right)}, q=1, \ldots, Q, \theta_{Q}=0
$$

Where $z_{i}$ denotes a set of observable characteristics (e.g., socio-demographics such as age, income and gender) that enter the model for class membership. 
$P_{i t \mid q}$ is the choice probability that individual $i$, conditional to belonging to class $\mathrm{q}(\mathrm{q}=1, \ldots, \mathrm{Q})$, chooses alternative $\mathrm{j}$ from a particular set $\mathrm{J}$, comprised of $\mathrm{j}$ alternatives, in a particular choice occasion $\mathrm{t}$, and is represented as:

$$
P_{i t \mid q}(j)=\frac{\exp \left(x_{i t, j}^{\prime} \beta_{q}\right)}{\sum_{j=1}^{J} \exp \left(x_{i t, j}^{\prime} \beta_{q}\right)}
$$

$\beta_{q}, \theta_{q}$ are the parameters to be estimated. With the parameters $\beta_{q}, \theta_{q}$ in hand, we used Bayes'

theorem to obtain respondent-specific (posterior) estimates of the class probability $\widehat{H}_{q \mid i}$, conditioned on their estimated choice probabilities:

$$
\widehat{H}_{q \mid i}=\frac{\widehat{P}_{i \mid q} \widehat{H}_{i q}}{\sum_{q=1}^{Q} \hat{P}_{i \mid q} \widehat{H}_{i q}}
$$

The computed respondent-specific (posterior) estimates of the class probability are then used in the beta regression analysis to profile the members of each class. The beta regression analysis is described at the end of this section.

To determine the number of classes, the Consistent Akaike Information Criterion (CAIC), and the Bayesian Information Criterion (BIC) were used. Their computation and values corresponding to LCM with 2 to 6 classes are displayed in Table 2. In what follows we report the results from the estimation of LCM with 5 classes because is the model resulted in the lowest CAIC and BIC values (Table 2). The results from the estimation of the RPL and the LCM models are presented in Table 3

\section{[Insert Table 2 about here]}

In addition to the estimation of respondents' preferences, choice data is often used to calculate WTP. WTP is commonly expressed as the negative ratio of the non-price attribute coefficient to the price coefficient: 


$$
W T P_{\text {non-price attribute }}=-\frac{\beta_{\text {non price attribute }}}{\beta_{\text {price }}}
$$

The calculated value represents respondents' marginal WTP. For the attributes coded as continuous (e.g., DB), the calculated value represents respondents' WTP for a one unit (\$1) increase of the continuous attribute. In the case of categorical attributes, the calculated value represents respondents' WTP for the attribute's level of interest (e.g., benefit period of a lifetime) with respect to the baseline level (e.g., benefit Period of 1 year). The computed WTP values are displayed in Table 4.

After classifying respondents in 5 classes, we characterized each class using, among others, information on respondents' attitudes and socio-demographic characteristics. The explanatory variables used in the classes' characterization are described in Table 5. Those variables were regressed against respondent-specific (posterior) estimates of the class probability $\widehat{H}_{q \mid i}$. Since the dependent variable is in form of probability, we estimated a Beta regression model for each segment. The results are displayed in Table 6.

\subsection{Limitations}

Our analysis is not without limitations including the fact that individuals exhibit cognitive limitations that might limit the ability to carry out the comparisons that underpin purchase decisions, and hence the small market size for LTCI may be due to those limitations. Individuals may also suffer from some level of choice overload, or fatigue which limits them in making optimal insurance choices.

\section{Results}

The RPL models were estimated using Modified Latin Hypercube Sampling draws with 1200 simulations, considering repeated choice situations. All the estimation was conducted using the 
Stata software. The results displayed in Table 2 show that the RPL model as well as the LCM with 5 classes fit the data better than the conditional logit based on the CAIC and BIC values.

The results from the RPL models show that the coefficients corresponding to the main effects are significant and with the expected sign. That is, we find a negative sign for the premium coefficient and positive signs for all the rest. The negative sign of the coefficient "None" suggests that respondents tended to prefer to buy an insurance as opposed to the opt-out alternative. It is important to recall that we have excluded respondents who chose "None" for all choices presented. Most of the standard deviation parameters, which indicate how the valuation of the entire sample spreads around the estimated means, are significant, indicating that the preferences are heterogeneous among the sampled consumers. The estimated cost coefficient is negative and statistically significant, indicating that respondents will tend to choose lower cost LTCI, other attributes constant.

\section{[Insert 3 about here]}

\subsection{Daily benefit}

The results from the RPL model, displayed in Table 3, show that respondents are more likely to choose an insurance policy that offers a higher daily payment toward buyer's long-term care costs holding premiums constant. Not surprisingly respondents value more coverage to less. Results displayed in Table 4 show that respondents' WTP for the policy increases by $\$ 0.22$ for each $\$ 1$ increase in the daily benefit payment of the policy. For example, respondents estimated WTP increases by $\$ 55(0.22 \times 250)$ when the daily benefit payment increases from $\$ 50$ to $\$ 300$. Nonetheless, responses display some significant heterogeneity. Table 4 shows that among all respondents, we find some heterogeneity across classes. Class 1 respondents (18\% of respondents) 
were found to be willing to pay the highest price premium $(\$ 1.45)$, while the members of Class 2 are willing to pay a premium as low as $\$ 0.17$ for each $\$ 1$ increase in the daily benefit payment.

\subsection{Benefit Period}

We find that respondents are more likely to buy insurance that provide benefits that last for their lifetimes compared to insurance that provides finite benefits for only one year (also respondents have higher preferences for lifetime policy than policy that offer benefits for 5 years or 3 years etc.). In terms of WTP, respondents are willing to pay an incremental premium to the total of $\$ 157.15$ per month for a policy that offers lifetime benefits over a policy that offers a 1-year benefit. According to the American Association for Long-Term Care Insurance (2015), the average cost in 2013 of an LTC insurance policy for a couple aged 55 with $\$ 162,000$ each in benefits and 3 percent annual inflation protection was $\$ 3,725$ a year or $\$ 310.42$ per month (or $\$ 155.21$ per person). Note the typical policy had a duration of coverage of under four years.

Nonetheless, the results from the latent class analysis (Table 4) show that the members of Class 1 are willing to pay an annual premium of $\$ 11,196$, which is significantly higher than the average annual premium. As in other attributes, Class 2 respondents were found to be only willing to pay a low premium ( $\$ 95.61$ per month or $\$ 1147$ per year) for a policy that offers lifetime benefits compared to a policy that offers a 1-year benefit. The results displayed in Table 4 also show that the members of the remaining classes are willing to pay premiums that are close to average respondent's premium $(\$ 157.15)$. Similar patterns were also found in the case of insurance policies that offer 5 and 3-year benefits. Again, the average premium was well below the actuarially fair premium for a lifetime policy.

Furthermore, the estimates for the duration of the benefit period (Table 4) show a larger value placed on insurance policies of longer duration but the incremental value is less than 
proportional. The WTP estimates (Table 4) show a valuation of $\$ 86.27$ per month for a policy that offers 5 years benefits compared to one that offers a 1-year benefit. The valuation for a policy covering three years compared to 1 -year coverage was estimated to be $\$ 73.10$ per month. Thus, the three-year policy is valued at $85 \%$ of the 5 -year policy more than the difference in expected benefit. Similar patterns were observed in the case of the estimates from the latent class analysis (Table 4). For instance, members of Class 1, Class 2, Class 3, Class 4 and Class 5 value the 3-year policy at $61 \%, 78 \%, 110 \%, 88 \%$ and $70 \%$, respectively, of the 5 -year policy more than the difference in expected benefit. Notice that the standard deviations are significant, which implies that consumers' preferences are heterogeneous.

\subsection{Deductible Period and Health Requirements}

We find that the length of the elimination (or deductible) period influences the value of the insurance policy. Results displayed in Table 4 show that the average WTP increases by $\$ 7.79$ for a one-month reduction of the deductible period. The results also show that respondents' WTP per month reduction in the elimination period varies considerable across classes, being positive and significantly higher average respondent’s WTP in Class 1 (\$327.27), Class 3 (\$121.06) and Class 4 (\$45.04). In difference with Class1, 3 and 4, respondents in Class 2 and Class 5 were found to discount the reduction of the deductible period (\$-20.38 and \$64.32, respectively), which indicate that the members of these two classes prefer a larger deductible period. However, this evidence is at odds a general preference for smaller deductibles (Bhargava et al, 2017).

Respondents' insurance policy valuation is sensitive to the existence of "health requirements". That is, they show that LTCI products that are not medically under-written are more likely to be chosen than LTCI that requires an examination holding price constant. The results displayed in Table 4 show that respondents are willing to pay $\$ 25.48$ more for an insurance policy that does not require a 
medical examination and a doctor's signature for purchase. The differential premium costs estimated by actuaries is considerably larger than our WTP to forego medical underwriting. As shown in Table 4, respondents' WTP for the attribute 'health requirement' exhibits heterogeneity. Members of Class 1 and Class 4 are willing to pay a premium ( $\$ 176.29$ and $\$ 15.35$, respectively) for LTCI that does not require an examination. Nonetheless, the results show respondents in Class 2 and Class 3 are indifferent between an LTCI product that requires a medical exam and a doctor's signature for purchase and policy insurance that does not necessitate these requirements. Interestingly, members of Class 5 were found to prefer policy insurance that requires a medical exam and a doctor's signature and are willing to pay pray a premium for it of $\$ 93.31$.

\subsection{Type of Insurer and Enrollment}

The results in Table 3 reveal that respondents are more likely to purchase insurance that is provided by a private company than an insurance provided by the federal government. Regarding their WTP, the results show that respondents are willing to pay a price premium of $\$ 13.90$ for LTCI provided by a private company than LTCI provided by the federal government. The results from the latent class analysis (Table 4) show that the preference for LTCI provided by a private company is not shared by all respondents. In fact, the results show that members of Class 3 and Class 5 are willing to pay a price premium ( $\$ 105.11$ and $\$ 507.16$, respectively) for LTCI provided by a private company, while members of Class 2 were found to be indifferent between LTCI provided by a private sources or government. Interestingly members of Class 1 , who were found to be willing to pay the highest premiums for the attributes daily benefit and benefit period as well as for a policy insurance that provide lifetime benefits and shorter deductible period and does not involve medical underwriting. Class 4 prefer policy insurance provided by the federal government and are willing to pay a premium of $\$ 78.65$ and $\$ 23.75$, respectively. This result is consistent with the fact that some 
consumers value being offered a choice of insurer. Surprisingly this is in the context of an industry where there have been many companies that have withdrawn from the market

\section{[Insert Table 4 about here]}

Our results show that respondents' value LTCI that is voluntary and not mandatory. The results displayed in Table 4 show that respondents are willing to pay $\$ 74.71$ more for voluntary plan than for universal plan. This valuation is inconsistent with what has been learned about the functioning of LTCI markets and the market failures produced by adverse selection. The estimated standard deviation for the attribute type of enrollment (Table 3) is statistically significant, indicating that respondents' preferences are heterogeneous and, hence, a group of them are willing pay more for universal plan than for voluntary plan. As a matter of fact, the results displayed in Table 4 show that while the majority of respondents (Class 3,4 and 5) are willing to pay a premium for voluntary plan, being largely higher in Class $3(\$ 628.85)$ and Class $5(\$ 557.50)$ than average respondent's premium (\$81.97), $18 \%$ of respondents (Class 1) are willing to pay a premium equal to $\$ 119.24$ for universal plan. Members of Class 2 were found to be indifferent between voluntary and universal policy insurance.

\subsection{Heterogeneity}

In the previous sections we describde how respondent preferences for insurance policy attributes vary across respondent groups. Below, we highlight the features that characterize the preferences of the members of each the five classes (which we then label according to its characteristics) as well as profiling them using the results from the Beta regression that are displayed in Table 6. This can be of some help in designing policy insurances that are tailored to the needs of the members of each segment and target them more efficiently. Notice that information that will be presented in the next few paragraphs is based on the results displayed in Tables 6 and 7., specifically we provide a title description of each class of choice respondent as below: 


\section{[Insert Tables 6 and 7 about here]}

Insurance universalists (Class 1): this class includes $18 \%$ of respondents. It is the class whose members are willing to pay the highest premium for policy for insurance that offers higher daily benefit, a longer benefit period, a shorter deductible period and does not involve medical underwriting. Interestingly, their premium for insurance that provides benefits for lifetimes (\$932.98) is almost six times the sample average WTP $(\$ 157.15)$ and three times the average market price for all LTCI (\$310.42). Class 1 is the unique class whose members prefer universal over voluntary policy insurance and have the highest chance to buy LTC insurance provided by the government. The results presented in Table 6 show that compared with the members of the other classes, members of Class 1 are more likely to have private long-term care insurance policy. They are also more likely be female and overweight or obese. Nonetheless, they are less likely to be white person and have children.

Rational insurance purchasers (Class 2): the members of this segment (15\% of respondents) are characterized by respondents with the lowest willingness to pay a premium for insurance that offers higher daily benefit, longer benefit period, shorter deductible period and that does not require medical exam and a doctor's signature. Interestingly, for the member of this class, the attributes health requirement, type of insurer and type of enrolment are not important for their choice decision. This implies that they are likely to only look value the attributes daily benefits, benefit period and the length of the deductible period and ignore the other attributes when deciding to by LTC insurance. Compared with the other classes, the results presented in Table 6 show that the member of Class 2 are more likely to have a high income but less likely to be obese and do not agree with the idea that it is the government's responsibility to help pay for the long-term care needs of all Americans.

Insurance consumerists (Class 3): This class (10\% of respondents) stands out by being the class whose members are willing to pay the highest premium for a voluntary plan over universal plan. It is noteworthy that they are also respondents with higher premium for insurance provided by a 
private company and do not consider under-writing as an important factor when purchasing and LTC insurance. Therefore, the unique policy that the members of Class 3 are likely to purchase should offer higher daily benefit, benefits for lifetime and shorter deductive period. The policy should be provided by a private company and most importantly should be voluntary. According to the results displayed in Table 6, the members of Class 3 are more likely to have a household income that ranges from $\$ 15,000$ to $\$ 39,999$. They are also more likely to support the idea that it is not their responsibility to provide unpaid care for elderly or disabled family members, but it is the government's or relatives' responsibility. Furthermore, they are less likely to be overweight or obese people.

Default purchasers (Class 4): This is the largest class, including 44\% of sampled respondents. Our results showed most of these respondents prefer a LTC insurance policy delivered by the federal government in addition of offering higher daily benefit, benefits for lifetime and shorter deductive period, requiring prior medical exam and being voluntary. The Beta regression analysis (Table 6) showed that, in comparison with the other classes, the members of Class 4 are more likely to be males and support the argument that if the elderly or disabled family members can no longer pay for the nursing home or home care they need, relatives should help to pay for their long-term care. Furthermore, they tend to have lower incomes.

Private Purchasers (C5): is the class whose members are willing to pay the highest premium (\$507.16) for an LTC insurance provided by a private company. It is also the only class whose members are willing to pay a premium for an LTC insurance that is under-written. They also stand out by being the respondents with the highest premium for longer deductible period. Their preferences for the remaining attributes of an LTC insurance policy are in line with the preferences of the rest of respondents. The members of Class 5 are supporter of the argument that it is the government's responsibility to help pay for the long-term care needs of all Americans but not relatives' responsibility. They are more likely to be white, elder people and own the primary place where they live and less likely to have children. 


\subsection{Valuation}

Using our WTP estimates, it is possible to estimate the average marginal WTP by type of consumer. Our estimates suggest that the LTCI premium is on average the most important factor to potential insurer purchasers. Relative to the premium, respondents are less concerned about medical underwriting and whether the policy is offered by private insurers or the government. These estimates should be interpreted as 'simple approximations' of private valuations of WTP for LTCI. They do not account for various social benefits such as the positive externalities on family caregivers from having LTCI, and potential Medicaid savings that stem from individuals purchasing LTCI. Hence, our estimates are lower bound estimates which are overall suggestive of the need of a subsidy for some respondents. The probability of a policy uptake declines when the policy is compulsory other factors equal. However, it is well established that by making LTCI compulsory premiums are reduced dramatically and the need to under-write largely goes away. Both latter attributes are valued by consumers.

One way to illustrate the relative value of different policy options is to compare the marginal WTP of extreme insurance policy alternatives in terms of how generous the policy is to the consumer (daily benefit, low deductible, high benefit). Table 8 illustrates the comparison of between two options that differ in all the attributes. On average, the marginal WTP for the most a 'generous' (Policy B) compared to the least generous (Policy A)' in terms of valued market attributes amount to $\$ 342$ However, the estimates are subject to significant heterogeneity. While the insurance universalist (Class1) group's marginal WTP is $\$ 1,909$ and the so-called insurance consumerists (Class 3) and private purchasers (Class 5) are willing to pay $\$ 1392$ and $\$ 1115$ respectively. At the other end, so-called rational insurers (Class2) and default consumers (Class4) are only willing to pay $\$ 68$ and $\$ 379$ respectively at the margin. 


\section{Conclusion}

We have employed a discrete choice experiment (DCE) to study the choice of LTCI in the United States. This is important given that the market for LTCI in the US is the world largest but has exhibited a very sluggish growth over time. DCE estimates are best thought of as estimates of potential private demand and may represent a high upper bound on the policies people would purchase, or whether they would purchase any policy at all. We have undertaken two alternative strategies. On a first instance, we examined respondents' preferences and WTP for LTCI attribute using the random parameter logit. Next, we have employed a latent class model approach to investigate the heterogeneity of respondents' preferences and WTP.

Our results make evident that bulk of respondents would at least consider the purchase of LTCI, as only $19 \%$ of respondents chose the opt-out alternative in all the choice sets. Our DCE examine the choices and its valuation of the remaining individuals. We find that on average individuals are highly sensitive to LTCI costs, and that the average WTP for a lifetime LTCI policy is significantly heterogeneous across individuals. In fact, we find that although the WTP difference between the most generous policy amounts to $\$ 342$, it varies between $\$ 1909$ for some segment of the market to $\$ 68$ for another. This suggests that part of the observed limited LTCI uptake is, in part, due to a low valuation of LTCI that is inconsistent with the market's ability to offer such prices that are attractive to most consumers. Although the social value of this insurance may exceed the private value, behavioral phenomenon may cause an under valuing of the private benefits which give rise to an efficiency case for some subsidization. Some policies in U.S. states have offered tax-based subsidies for the purchase of LTCI. However the value of those subsidies was very small and accrued primarily to high income households as a results they met with little success (Stevenson,et al 2009; Goda 2011). Our findings suggest that there might be scope for insurance redesign to address some of the behavioral constraints to insurance take up. 
Another important finding is that a voluntary insurance contract is more highly valued than a compulsory one. This is consistent with a preference for choice. The value put on voluntary policy is important in the context of the US, and consistent with the idea that when individual's heterogeneity is large, then options that offer a choice are preferred as they preserve 'consumer sovereignty' (Becker and Zweifel, 2004). As a market design matter, it is also highly incompatible with what has been learned about the ability to address the adverse selection problem. 


\section{References}

AHIP (2017), https://www.ahip.org/who-buys-long-term-care-insurance

Allaire, B. T., Brown, D. S., \& Wiener, J. M. (2016). Who Wants Long-Term Care Insurance? A Stated Preference Survey of Attitudes, Beliefs, and Characteristics. INQUIRY: The Journal of Health Care Organization, Provision, and Financing, 53, 0046958016663728.

American Association for Long-Term Care Insurance. (2015). Long-Term Care Insurance Fact-Statistics. Westlake Village, CA. Available at http://www.aaltci.org/long-termcareinsurance/learning-center/fast-facts.php.

Bhargava, S., Loewenstein, G., \& Sydnor, J. (2017). Choose to lose: Health plan choices from a menu with dominated option. The Quarterly Journal of Economics, 132(3), 1319-1372.

Becker, K., \& Zweifel, P. (2008). Age and choice in health insurance. The Patient: PatientCentered Outcomes Research, 1(1), 27-40.

Bergquist, S and Costa-Font, J and Swartz, K(2018) Long-term care partnerships: are they fit for purpose? Journal of the Economics of Ageing, 12. 151-158

Berridge, K. C., \& Robinson, T. E. (2003). Parsing reward. Trends in neurosciences, 26(9), 507513.

Brau, R., \& Lippi Bruni, M. (2008). Eliciting the demand for long- term care coverage: a discrete choice modelling analysis. Health Economics, 17(3), 411-433.

Braun, A., Schmeiser, H., \& Schreiber, F. (2016). On consumer preferences and the willingness to pay for term life insurance. European Journal of Operational Research, 253(3), 761-776.

Brown, J. R., Goda, G. S., \& McGarry, K. (2012). Long-term care insurance demand limited by beliefs about needs, concerns about insurers, and care available from family. Health Affairs, 31(6), 1294-1302.

Brown, Jeffrey R., and Amy Finkelstein (2007). "Why is the market for long-term care insurance so small?." Journal of Public Economics 91, no. 10 (2007): 1967-1991.

Brown, J. R., \& Finkelstein, A. (2008). The interaction of public and private insurance: Medicaid and the long-term care insurance market. American Economic Review, 98(3), 1083-1102.

Butler, L. Claypool, H., Feder, J., Ruttledge, L., \& Stein, J. (2013). A Comprehensive Approach to Long-Term Services and Supports. Washington, DC: Long-Term Care Commission. Available at http://www.medicareadvocacy.org/wpcontent/uploads/2013/10/LTCCAlternativeReport.pdf.

Coe, N. B., Skira, M. M., \& Van Houtven, C. H. (2015). Long-term care insurance: Does experience matter?. Journal of health economics, 40, 122-131.

Cohen, M.A., Kaur, R., \& Darnell, B. (2013). Exiting the Market: Understanding the Factors Behind Carriers' Decision to Leave the Long-Term Care Insurance Market. Waltham, MA: LifePlans, Inc. for the Office of the Assistant Secretary for Planning and Evaluation/U.S. 
Department of Health and Human Services. Available at https://aspe.hhs.gov/report/exitingmarket-understanding-factors-behind-carriers-decisionleave-long-term-care-insurancemarket.

Costa-Font, J., \& Rovira-Forns, J. (2008). Who is willing to pay for long-term care insurance in Catalonia?. Health Policy, 86(1), 72-84.

Costa-Font, J. (2017). "Institutionalization aversion" and the willingness to pay for home health care. Journal of Housing Economics, 38, 62-69.

Gabaix, X., \& Laibson, D. (2006). Shrouded attributes, consumer myopia, and information suppression in competitive markets. The Quarterly Journal of Economics, 121(2): 505-540.

Gottlieb, D., \& Mitchell, O. S. (2015). Narrow framing and long-term care insurance (No. w21048). National Bureau of Economic Research.

Greene, W. H., \& Hensher, D. A. (2003). A latent class model for discrete choice analysis: contrasts with mixed logit. Transportation Research Part B: Methodological, 37(8), 681-698.

Hensher, D. A., Ho, C., \& Mulley, C. (2015). Identifying preferences for public transport investments under a constrained budget. Transportation Research Part A: Policy and Practice, 72, 27-46.

Johnson, F., Lancsar, E., Marshall, D., Kilambi, V., Mühlbacher, A., Regier, D.A., Bresnahan, B.W., Kanninen, B., \& Bridges, J.F. (2013). Constructing experimental designs for discretechoice experiments: Report of the ISPOR Conjoint Analysis Experimental Design Good Research Practices Task Force. Value Health, 16(1), 3-13.

Kemper, P., Komisar, H.L., \& Alecxih, L. (2005). Long-term care over an uncertain future: What can current retirees expect? Inquiry, 42(4), 335-350.

Krueger, A B. \& Kuziemko, I, (2013). The demand for health insurance among uninsured Americans: Results of a survey experiment and implications for policy, Journal of Health Economics, Elsevier, vol. 32(5), pages 780-793

Kunreuther, H., and Slovic, P. (1978), 'Economics, Psychology and Protective Behavior,' American Economic Review, vol. 68, pp. 64-69.

Loewenstein, G., Friedman, J. Y., McGill, B., Ahmad, S., Linck, S., Sinkula, S. \& Madrian, B. C. (2013). Consumers' misunderstanding of health insurance. Journal of Health Economics, 32(5): 850-862.

Marshall, S., McGarry, K., \& Skinner, J. S. (2011). The risk of out-of-pocket health care expenditure at the end of life. In Explorations in the Economics of Aging (pp. 101-128). University of Chicago Press.

McGarry, B. E., Tempkin-Greener, H., Grabowski, D. C., Chapman, B. P., \& Li, Y. (2017). Consumer Decision-Making Abilities and Long-Term Care Insurance Purchase. The Journals of Gerontology: Series B.

Nieboer, Anna P., Xander Koolman, and Elly A. Stolk. "Preferences for long-term care services: Willingness to pay estimates derived from a discrete choice experiment." Social Science \& Medicine 70, no. 9 (2010): 1317-1325. 
Wiener, J.M., Illston, L.H., \& Hanley, R.J. (1994). Sharing the Burden: Strategies for Public and Private Long-Term Care Insurance. Washington, DC: Brookings Institution.

Wiener JM, Anderson W, Khatutsky G, Kaganova Y, O'Keeffe J (2013). Medicaid Spend Down: New Estimates and Implicationsfor Long-term Services and Supports Financing Reform. Washington, DC: RTI International; 2013 
Table 1: Long-Term Care Insurance Attributes Included in the Discrete Choice Experiment

\begin{tabular}{|c|c|c|}
\hline Attribute & Description & Levels \\
\hline Daily Benefit & $\begin{array}{l}\text { How much the policy pays per day toward } \\
\text { your long-term care costs }\end{array}$ & $\$ 300, \$ 175, \$ 100, \$ 50$ per day \\
\hline Benefit Period & How long the policy provides benefits for & Lifetime, 5 years, 3 years, 1 year \\
\hline Deductible Period & $\begin{array}{l}\text { When you first become disabled, how long } \\
\text { before the insurance company will pay for } \\
\text { services }\end{array}$ & $\begin{array}{l}\text { None, } 1 \text { month, } 3 \text { months, } 6 \\
\text { months }\end{array}$ \\
\hline Health Requirements & $\begin{array}{l}\text { Whether the plan requires a medical exam } \\
\text { and a doctor's signature for purchase }\end{array}$ & None; Healthy and not disabled \\
\hline Type of Insurer & The sponsor or seller of the insurance plan & $\begin{array}{l}\text { Private company; federal } \\
\text { government }\end{array}$ \\
\hline Monthly Premium Cost & $\begin{array}{l}\text { The amount you pay each month to } \\
\text { maintain coverage }\end{array}$ & $\$ 30, \$ 100, \$ 225, \$ 400$ per month \\
\hline Type of Enrolment & $\begin{array}{l}\text { Whether purchase of the insurance plan } \\
\text { shown was required by law }\end{array}$ & $\begin{array}{l}\text { Voluntary: no one must buy } \\
\text { insurance; } \\
\text { Universal plan: everyone must } \\
\text { buy this policy }\end{array}$ \\
\hline
\end{tabular}


Table 2: Information on the converged latent segment models and a random parameters logit model

\begin{tabular}{cccccc}
\hline $\begin{array}{c}\text { Number } \\
\text { of Classes }\end{array}$ & $\begin{array}{c}\text { Log likelihood } \\
\text { at convergence } \\
(\mathbf{L} \mathbf{L})\end{array}$ & $\begin{array}{c}\text { Number } \\
\text { of parameters }\end{array}$ & $\begin{array}{c}\text { Number } \\
\text { of observations }\end{array}$ & CAIC & BIC \\
\hline 2 & -33408.3 & 41 & 11833 & 67244.19 & 67203.19 \\
3 & -33103.5 & 73 & 11833 & 66968.57 & 66895.57 \\
4 & -32924.4 & 105 & 11833 & 66944.14 & 66839.14 \\
$\mathbf{5}$ & $-\mathbf{3 2 7 1 3 . 9}$ & $\mathbf{1 3 7}$ & $\mathbf{1 1 8 3 3}$ & $\mathbf{6 6 8 5 6 . 8 2}$ & $\mathbf{6 6 7 1 9 . 8 2}$ \\
6 & -32632.6 & 169 & 11833 & 67028.13 & 66859.13 \\
RPL model & -34430.58 & 20 & 12476 & 69069.79 & 69049.79 \\
\hline
\end{tabular}

Note: CAIC (Consistent Akaike Information Criterion) is calculated using: $-2 * \mathrm{LL}+(\ln (\mathrm{N})+1) *$ PBIC (Bayesian Information Criterion) is calculated using: $-2 * \mathrm{LL}+\ln (\mathrm{N}) * \mathrm{P}$

RPL stands for Random parameter logit 
Table 3: Estimated consumers' preferences

\begin{tabular}{|c|c|c|c|c|c|c|c|c|c|c|c|c|c|c|}
\hline \multirow[t]{2}{*}{ Variables } & \multicolumn{4}{|c|}{$\begin{array}{c}\text { Random parameter } \\
\text { logit model (RPL) }\end{array}$} & \multicolumn{10}{|c|}{5 class model } \\
\hline & \multicolumn{2}{|c|}{ Mean } & \multicolumn{2}{|c|}{$\begin{array}{l}\text { Std. } \\
\text { deviation }\end{array}$} & \multicolumn{2}{|c|}{ Class 1} & \multicolumn{2}{|c|}{ Class 2} & \multicolumn{2}{|c|}{ Class 3} & \multicolumn{2}{|c|}{ Class 4} & \multicolumn{2}{|c|}{ Class 5} \\
\hline None & & & & & -2.559 & $* * *$ & - & $* * *$ & -13.268 & $* * *$ & 0.499 & $* * *$ & 0.757 & $* * *$ \\
\hline Daily Benefit & -0.857 & $\begin{array}{l}* * * \\
* * *\end{array}$ & $\begin{array}{r}-1.141 \\
0.002\end{array}$ & $\begin{array}{l}* * * \\
* * *\end{array}$ & 0.002 & $* * *$ & $\begin{array}{l}5.862 \\
0.003\end{array}$ & $* * *$ & 0.003 & $* *$ & 0.002 & $* * *$ & 0.002 & $* * *$ \\
\hline Benefit Period-Lifetime & 1.333 & $* * *$ & -0.738 & $* * *$ & 1.243 & $* * *$ & 1.590 & $* * *$ & 1.072 & $* * *$ & 1.647 & $* * *$ & 0.600 & $* * *$ \\
\hline Benefit Period-5years & 0.732 & $* * *$ & 0.140 & & 0.711 & $* * *$ & 1.138 & $* * *$ & 0.746 & $* *$ & 0.914 & $* * *$ & 0.311 & $* *$ \\
\hline Benefit Period-3years & 0.620 & $* * *$ & -0.035 & & 0.436 & $* * *$ & 0.887 & $* * *$ & 0.818 & $* * *$ & 0.805 & $* * *$ & 0.217 & \\
\hline Deductible Period & 0.066 & $* * *$ & -0.029 & & 0.314 & $* * *$ & 0.339 & $* * *$ & 0.664 & $* * *$ & 0.450 & $* * *$ & 0.207 & $* *$ \\
\hline Health Requirement & 0.216 & $* * *$ & -0.597 & $* * *$ & 0.235 & $* * *$ & 0.175 & & 0.422 & & 0.154 & $* * *$ & 0.300 & $* * *$ \\
\hline Type of Insurer & 0.096 & $* * *$ & 0.665 & $* * *$ & -0.105 & $* *$ & 0.168 & & 0.577 & $* * *$ & 0.238 & $* * *$ & 1.632 & $* * *$ \\
\hline Type of Enrolment & 0.695 & $* * *$ & 0.997 & $* * *$ & -0.159 & $* *$ & 0.082 & & 3.451 & $* * *$ & 0.474 & $* * *$ & 1.794 & $* * *$ \\
\hline Cost & -0.008 & $* * *$ & -0.006 & $* * *$ & -0.001 & $* * *$ & 0.017 & $* * *$ & -0.005 & $* * *$ & $0.010^{-}$ & $* * *$ & 0.003 & $* * *$ \\
\hline Class share & 1 & & & & 0.18 & & 0.15 & & 0.10 & & 0.44 & & 0.13 & \\
\hline
\end{tabular}

$(* * *)(* *)$ and $(*)$ denote statistical significance at $(1 \%),(5 \%)$ and $(10 \%)$ level, respectively

Table 4: Consumers' marginal willingness to pay (MWTP)

\begin{tabular}{|c|c|c|c|c|c|c|c|c|c|c|c|c|}
\hline \multirow{4}{*}{$\begin{array}{l}\text { Variables } \\
\begin{array}{l}\text { Daily Benefit } \\
\text { Benefit Period-Lifetime }\end{array}\end{array}$} & \multicolumn{2}{|c|}{ RPL } & \multicolumn{10}{|c|}{5 class model } \\
\hline & & & \multicolumn{2}{|c|}{ Class 1} & \multicolumn{2}{|c|}{ Class 2} & \multicolumn{2}{|c|}{ Class 3} & \multicolumn{2}{|c|}{ Class 4} & \multicolumn{2}{|c|}{ Class 5} \\
\hline & 0.22 & $* * *$ & 1.45 & $* * *$ & 0.17 & $* * *$ & 0.50 & $*$ & 0.20 & $* * *$ & 0.75 & $* * *$ \\
\hline & 157.15 & $* * *$ & 932.98 & $* * *$ & 95.61 & $* * *$ & 195.24 & $* * *$ & 164.65 & $* * *$ & 186.65 & $* * *$ \\
\hline Benefit Period-5years & 86.27 & $* * *$ & 533.88 & $* * *$ & 68.46 & $* * *$ & 135.92 & $* * *$ & 91.45 & $* * *$ & 96.73 & $* *$ \\
\hline Benefit Period-3years & 73.10 & $* * *$ & 327.27 & $* * *$ & 53.34 & $* * *$ & 149.04 & $* * *$ & 80.49 & $* * *$ & 67.51 & $*$ \\
\hline Deductible Period & 7.79 & $* * *$ & 236.00 & $* *$ & 20.38 & $* * *$ & 121.06 & $* * *$ & 45.04 & $* * *$ & -64.32 & $*$ \\
\hline Health Requirement & 25.48 & $* * *$ & 176.29 & $* *$ & 0.00 & & 0.00 & & 15.35 & $* * *$ & -93.31 & $* *$ \\
\hline Type of Insurer & 11.29 & $* * *$ & -78.65 & $*$ & 0.00 & & 105.11 & $* * *$ & -23.75 & $* * *$ & 507.16 & $* * *$ \\
\hline Type of Enrolment & 81.97 & $* * *$ & -119.24 & $* *$ & 0.00 & & 628.85 & $* * *$ & 47.36 & $* * *$ & 557.50 & $* * *$ \\
\hline Class share & 1 & & 0.18 & & 0.15 & & 0.10 & & 0.44 & & 0.13 & \\
\hline
\end{tabular}

$(* * *)(* *)$ and $(*)$ denote statistical significance at $(1 \%),(5 \%)$ and $(10 \%)$ level, respectively 
Table 5: Description of the segment membership variables

\begin{tabular}{|c|c|}
\hline Variables & Description \\
\hline Risk & $\begin{array}{l}\text { Willingness to take risks. The variable is measured on a on the scale of } 0 \text { to } 10 \\
\text { where } 0 \text { represents "not at all willing" to take risks and } 10 \text { represents "very } \\
\text { willing" to take risks. }\end{array}$ \\
\hline Ownership & $\begin{array}{l}\text { Whether the respondent owns the primary place where he/she lives (coded as } \\
\text { 1) or not (coded as } 0 \text { ) }\end{array}$ \\
\hline Resp_own & $\begin{array}{l}\text { This variable is coded as } 1 \text { if the respondent agrees with the statement that "It } \\
\text { is this/her responsibility to provide unpaid care for elderly or disabled family } \\
\text { members", otherwise the variable is coded as } 0 \text {. }\end{array}$ \\
\hline Resp_family & $\begin{array}{l}\text { This variable is coded as } 1 \text { if the respondent agrees with the statement that "It } \\
\text { is the responsibility of children or other family members to provide unpaid } \\
\text { care for elderly or disabled family members", otherwise the variable is coded } \\
\text { as } 0 \text {. }\end{array}$ \\
\hline Resp_relatives & $\begin{array}{l}\text { This variable is coded as } 1 \text { if the respondent agrees with the statement that "If } \\
\text { elderly or disabled family members can no longer pay for the nursing home or } \\
\text { home care they need, relatives should help pay for their long-term care.", } \\
\text { otherwise the variable is coded as } 0 \text {. }\end{array}$ \\
\hline Resp_governement & $\begin{array}{l}\text { This variable is coded as } 1 \text { if the respondent agrees with the statement that "It } \\
\text { is the government's responsibility to help pay for the long-term care needs of } \\
\text { all Americans.", otherwise the variable is coded as } 0 \text {. }\end{array}$ \\
\hline Long_term & $\begin{array}{l}\text { This variable is coded as } 1 \text { if respondent has a private long-term care } \\
\text { insurance policy separate from your regular health or disability insurance and } \\
\text { is coded as } 0 \text { if he/she doesn't have it. }\end{array}$ \\
\hline Have_children & $\begin{array}{l}\text { This variable is coded as } 1 \text { if respondent has children and } 0 \text { if he/she doesn't } \\
\text { have children. }\end{array}$ \\
\hline Education_LHS & $\begin{array}{l}\text { This variable is coded as } 1 \text { if respondent revealed to have less than a high } \\
\text { school diploma and } 0 \text { otherwise. }\end{array}$ \\
\hline Education_HS & $\begin{array}{l}\text { This variable is coded as } 1 \text { if respondent revealed to have a high school } \\
\text { diploma or equivalent and } 0 \text { otherwise. }\end{array}$ \\
\hline Education_SC & $\begin{array}{l}\text { This variable is coded as } 1 \text { if respondent revealed to have some college } \\
\text { studies but not a degree and } 0 \text { otherwise. }\end{array}$ \\
\hline Age & This variable is continuous and represents respondent's age in years. \\
\hline
\end{tabular}


Table 5: Description of the segment membership variables (continued)

\begin{tabular}{ll}
\hline Variables & \multicolumn{1}{c}{ Description } \\
\hline White & $\begin{array}{l}\text { Respondent describes himself/herself as white, otherwise the variable is coded } \\
\text { as } 0\end{array}$ \\
Income2 & $\begin{array}{l}\text { Respondent revealed that his household's income is between } \$ 15,000 \text { to } \\
\$ 39,999, \text { otherwise the variable is coded as } 0\end{array}$ \\
Income3 & $\begin{array}{l}\text { Respondent revealed that his household's income is between } \$ 40,000 \text { to } \\
\$ 84,999, \text { otherwise the variable is coded as } 0\end{array}$ \\
Income4 & $\begin{array}{l}\text { Respondent revealed that his household's income is } \$ 85,000 \text { or more, } \\
\text { otherwise the variable is coded as } 0\end{array}$ \\
BMI_underweight & $\begin{array}{l}\text { Respondent's body mass index (BMI) is less than } 18.5, \text { otherwise the variable } \\
\text { is coded as } 0\end{array}$ \\
BMI_overwieight & $\begin{array}{l}\text { Respondent's body mass index (BMI) is between } 25 \text { to 29.9, otherwise the } \\
\text { variable is coded as } 0\end{array}$ \\
BMI_obese & $\begin{array}{l}\text { Respondent's body mass index (BMI) is between } 30 \text { or higher, otherwise the } \\
\text { variable is coded as } 0\end{array}$ \\
Gender & Respondent is male and 0 if she is female.
\end{tabular}


Table 6: Results from the Beta regression - estimated marginal effects (\% change)

\begin{tabular}{|c|c|c|c|c|c|c|c|c|c|c|}
\hline & Class 1 & & Class2 & & Class3 & & Class4 & & Class5 & \\
\hline Risk & 0.15 & $*$ & 0.25 & $* * *$ & 0.29 & $* * *$ & 0.26 & $* * *$ & -0.14 & $*$ \\
\hline Ownership & -16.34 & $* * *$ & 7.72 & $* * *$ & 7.30 & $* * *$ & -9.08 & $* * *$ & 58.64 & $* * *$ \\
\hline Resp_own & -0.80 & $* * *$ & -0.74 & $* * *$ & -1.09 & $* * *$ & -0.33 & $* * *$ & 0.76 & $* * *$ \\
\hline Resp_family & -0.05 & & 0.08 & & 0.03 & & 0.13 & $*$ & 0.11 & \\
\hline Resp_relatives & -6.97 & $* * *$ & -5.77 & $* * *$ & 7.37 & $* * *$ & 13.14 & $* * *$ & -35.53 & $* * *$ \\
\hline Resp_governement & -25.94 & $* * *$ & -40.64 & $* * *$ & 39.88 & $* * *$ & -31.86 & $* * *$ & 135.50 & $* * *$ \\
\hline Long_term & 35.91 & $* * *$ & -15.86 & $* * *$ & -15.72 & $* * *$ & -18.83 & $* * *$ & 35.66 & $* * *$ \\
\hline Have_children & -29.06 & $* * *$ & 13.06 & $* * *$ & 17.16 & $* * *$ & -1.23 & $* * *$ & 19.56 & $* * *$ \\
\hline Age & -0.01 & $* *$ & 0.00 & & 0.00 & & -0.01 & $*$ & 0.02 & $* * *$ \\
\hline Education_LHS & 0.39 & & -0.01 & & -0.07 & & 0.21 & & 0.12 & \\
\hline Education_HS & 0.40 & $* * *$ & 0.08 & & 0.27 & $* *$ & 0.04 & & -0.38 & $* * *$ \\
\hline Education_SC & 0.27 & $* * *$ & -0.05 & & 0.05 & & -0.14 & $*$ & -0.13 & \\
\hline White & -36.20 & $* * *$ & -14.11 & $* * *$ & 23.25 & $* * *$ & 3.21 & $* * *$ & 55.39 & $* * *$ \\
\hline Income2 & -28.37 & $* * *$ & 22.52 & $* * *$ & 28.82 & $* * *$ & -0.88 & $* * *$ & 13.42 & $* * *$ \\
\hline Income 3 & -41.73 & $* * *$ & 61.10 & $* * *$ & 20.98 & $* * *$ & -12.65 & $* * *$ & 38.25 & $* * *$ \\
\hline Income4 & -13.58 & $* * *$ & 68.86 & $* * *$ & -4.84 & $* * *$ & -18.26 & $* * *$ & 27.99 & $* * *$ \\
\hline BMI_underwieight & 0.85 & $*$ & 0.46 & & 0.47 & & 0.36 & & -0.28 & \\
\hline BMI_overwieight & 15.80 & $* * *$ & -4.44 & $* * *$ & -11.33 & $* * *$ & -5.68 & $* * *$ & 12.44 & $* * *$ \\
\hline BMI_obese & 12.11 & $* * *$ & -19.78 & $* * *$ & -4.56 & $* * *$ & 1.92 & $* * *$ & 4.36 & $* * *$ \\
\hline Gender & 38.26 & $* * *$ & 16.11 & $* * *$ & 16.29 & $* * *$ & -23.80 & $* * *$ & -7.38 & $* * *$ \\
\hline Log pseudolikelihood & \multicolumn{2}{|c|}{40891} & \multicolumn{2}{|c|}{42654} & \multicolumn{2}{|c|}{47014} & \multicolumn{2}{|c|}{32815} & \multicolumn{2}{|c|}{47550} \\
\hline Number of observations & \multicolumn{2}{|c|}{11,833} & \multicolumn{2}{|c|}{11,833} & \multicolumn{2}{|c|}{11,833} & \multicolumn{2}{|c|}{11,833} & \multicolumn{2}{|c|}{11,833} \\
\hline Wald chi square & \multicolumn{2}{|c|}{676761} & \multicolumn{2}{|c|}{432508} & \multicolumn{2}{|c|}{321261} & \multicolumn{2}{|c|}{654252} & \multicolumn{2}{|c|}{3620000} \\
\hline Prob > chi square & \multicolumn{2}{|c|}{0.0000} & \multicolumn{2}{|c|}{0.0000} & \multicolumn{2}{|c|}{0.0000} & \multicolumn{2}{|c|}{0.0000} & \multicolumn{2}{|c|}{0.0000} \\
\hline
\end{tabular}

$(* * *)(* *)$ and $(*)$ denote statistical significance at $(1 \%),(5 \%)$ and $(10 \%)$ level, respectively 
Table 7 Characteristics of the most preferred LTC insurance for the member of each class

\begin{tabular}{|c|c|c|c|c|c|}
\hline Attributes & Class 1 & Class 2 & Class 3 & Class 4 & Class 5 \\
\hline Daily Benefit & $\begin{array}{l}\text { The higher the } \\
\text { better } \\
\text { (\$1.45/day) }\end{array}$ & $\begin{array}{l}\text { The higher the } \\
\text { better } \\
\text { (\$0.17/day) }\end{array}$ & $\begin{array}{l}\text { The higher the } \\
\text { better } \\
(\$ 0.50 / \text { day })\end{array}$ & $\begin{array}{l}\text { The higher the } \\
\text { better } \\
(\$ 0.20 / \text { day })\end{array}$ & $\begin{array}{c}\text { The higher the } \\
\text { better } \\
(\$ 0.75 / \text { day })\end{array}$ \\
\hline Benefit Period & $\begin{array}{l}\text { Lifetime } \\
(\$ 932.98)\end{array}$ & $\begin{array}{l}\text { Lifetime } \\
(\$ 95.61)\end{array}$ & $\begin{array}{l}\text { Lifetime } \\
(\$ 195.24)\end{array}$ & $\begin{array}{l}\text { Lifetime } \\
(\$ 164.65)\end{array}$ & $\begin{array}{l}\text { Lifetime } \\
(\$ 186.65)\end{array}$ \\
\hline $\begin{array}{l}\text { Deductible } \\
\text { Period }\end{array}$ & $\begin{array}{l}\text { Shorter } \\
(\$ 236.00)\end{array}$ & $\begin{array}{c}\text { Longer } \\
(\$-20.38)\end{array}$ & $\begin{array}{l}\text { Shorter } \\
(\$ 121.06)\end{array}$ & $\begin{array}{l}\text { Shorter } \\
(\$ 45.04)\end{array}$ & $\begin{array}{c}\text { Longer } \\
(\$-64.32)\end{array}$ \\
\hline $\begin{array}{l}\text { Health } \\
\text { requirement }\end{array}$ & $\begin{array}{l}\text { No medical } \\
\quad \text { exam } \\
(\$ 176.29)\end{array}$ & $\begin{array}{l}\text { Not important } \\
\quad(\$ 0.00)\end{array}$ & $\begin{array}{l}\text { Not important } \\
\quad(\$ 0.00)\end{array}$ & $\begin{array}{l}\text { No medical } \\
\quad \text { exam } \\
(\$ 15.35)\end{array}$ & $\begin{array}{c}\text { Medical exam } \\
\quad(\$-64.32)\end{array}$ \\
\hline Type of Insurer & $\begin{array}{c}\text { Federal } \\
\text { government } \\
(\$-78.65)\end{array}$ & $\begin{array}{l}\text { Not important } \\
\quad(\$ 0.00)\end{array}$ & $\begin{array}{l}\text { Private } \\
\text { company } \\
(\$ 105.11)\end{array}$ & $\begin{array}{c}\text { Federal } \\
\text { government } \\
(\$-23.75)\end{array}$ & $\begin{array}{l}\text { Private } \\
\text { company } \\
(\$ 507.16)\end{array}$ \\
\hline $\begin{array}{l}\text { Type of } \\
\text { Enrolment }\end{array}$ & $\begin{array}{l}\text { Universal } \\
(\$-119.24)\end{array}$ & $\begin{array}{l}\text { Not important } \\
\qquad(\$ 0.00)\end{array}$ & $\begin{array}{l}\text { Voluntary } \\
(\$ 628.85)\end{array}$ & $\begin{array}{l}\text { Voluntary } \\
(\$ 47.36)\end{array}$ & $\begin{array}{l}\text { Voluntary } \\
(\$ 557.50)\end{array}$ \\
\hline
\end{tabular}

Table 8. Marginal WTP of Policy B compared to the baseline (Policy A)

\begin{tabular}{|c|c|c|c|c|}
\hline Attributes & $\begin{array}{l}\text { Baseline } \\
\text { policy (A) }\end{array}$ & New policy (B) & $\begin{array}{l}\text { Based on } \\
\text { estimates from: }\end{array}$ & $\begin{array}{l}\text { Price premium } \\
\text { for B with } \\
\text { respect to A }\end{array}$ \\
\hline Daily Benefit & $\$ 50$ & $\$ 250$ & RPL & $\$ 343.26$ \\
\hline Benefit Period & 1-year & Lifetime & Class 1 & $\$ 1909.38$ \\
\hline Deductible Period & 3 & 0 & Class 2 & $\$ 68.47$ \\
\hline Health Requirement & Yes & None & Class 3 & $\$ 1392.38$ \\
\hline Type of Insurer & Federal & Private company & Class 4 & $\$ 378.73$ \\
\hline Type of Enrolment & Universal & Voluntary & Class 5 & $\$ 1115.04$ \\
\hline
\end{tabular}


Figure 1: Example of a choice set presented in the set of the first five choice sets (DCE1)

\begin{tabular}{|c|c|c|}
\hline $\begin{array}{l}\text { INSURANCE } \\
\text { POLICY } \\
\text { FEATURE } \\
\end{array}$ & POLICY A & POLICY B \\
\hline Daily Benefit & $\$ 100 /$ day & $\$ 100 /$ day \\
\hline Benefit Period & 3 years & 5 years \\
\hline $\begin{array}{l}\text { Deductible } \\
\text { Period }\end{array}$ & 1 month & 3 months \\
\hline $\begin{array}{l}\text { Health } \\
\text { Requirements }\end{array}$ & Healthy and not disabled & None \\
\hline Type of Insurer & Private company & Private company \\
\hline $\begin{array}{l}\text { Monthly Premium } \\
\text { Cost }\end{array}$ & $\$ 100 /$ month & $\$ 200 /$ month \\
\hline \multicolumn{3}{|c|}{$\begin{array}{l}\text { G4d. Which policy, if any, would you choose } \\
\text { if these were the only options } \\
\text { available? }\end{array}$} \\
\hline
\end{tabular}

Source: Long-Term Care Awareness and Planning Survey, 2014. 
Figure 2: Example of a choice set presented in the set of the last three choice sets (DCE2) 


\begin{tabular}{|c|c|c|}
\hline $\begin{array}{l}\text { INSURANCE } \\
\text { POLICY } \\
\text { FEATURE }\end{array}$ & POLICY A & POLICY B \\
\hline Daily Benefit & $\$ 50 /$ day & $\$ 50 /$ day \\
\hline Benefit Period & 1 year & 1 year \\
\hline $\begin{array}{l}\text { Deductible } \\
\text { Period }\end{array}$ & 1 month & 1 month \\
\hline $\begin{array}{l}\text { Health } \\
\text { Requirements }\end{array}$ & None & Healthy and not disabled \\
\hline Type of Insurer & $\begin{array}{c}\text { Federal } \\
\text { government }\end{array}$ & $\begin{array}{c}\text { Federal } \\
\text { government }\end{array}$ \\
\hline $\begin{array}{l}\text { Monthly Premium } \\
\text { Cost }\end{array}$ & $\$ 30 /$ month & $\$ 100 /$ month \\
\hline $\begin{array}{l}\text { Voluntary or } \\
\text { Universal }\end{array}$ & $\begin{array}{l}\text { Universal plan. Everyone } \\
\text { must buy this. }\end{array}$ & $\begin{array}{l}\text { Voluntary. No one must buy } \\
\text { insurance. }\end{array}$ \\
\hline \multicolumn{3}{|c|}{$\begin{array}{l}\text { G5a. If you could choose between these, or } \\
\text { no insurance, which would you prefer? }\end{array}$} \\
\hline
\end{tabular}

Source: Long-Term Care Awareness and Planning Survey, 2014. 